\title{
Women as Canons in Engineering: Theorizing their Experiences and Exploits
}

\author{
Kehdinga George Fomunyam
}

\begin{abstract}
Globally theorizing women's experiences and exploits in engineering has attracted a lot of debates. Thus, efforts put in place to address under-representation among women in engineering, have been thwarted to accomplish Sustainable Development Goal (SDG) 5 on gender equality, in areas of preconception of engineering male-dominated profession, gender gaps in recruitment of women engineers, lack of gender-sensitive curriculum and low female involvement in Science, Engineering and Technology (SET) subjects are still lacking in Africa. With much sensitization on equality, yet women engineers are still plagued with gender disparity in Africa; hence the crux of this paper. This paper was guided by Liberal Feminist Theory focusing on gender inequality, exists as a consequence ofstereotypingdivision of labour and sexparity can be realized if vital institutions are re-patterned. This paper takes a broad look at women as canons in engineering alongside theorizing their experiences and exploits in Africa. Specifically, it explores how women engineers have made huge contributions; and to showcase their experiences and exploits, as well as its implications for Africa. Thus, to address these gaps, implementing of gender policies in eliminating all forms of under-representation of women in engineering was advocated.

Keywords: Africa, experiences, exploits, Feminist, women engineer, gender equality
\end{abstract}

\section{INTRODUCTION}

In the 21st century and in fourth industrial revolution (4IR) era, engineering advocates and feminist have clamored that experiences and exploits of women in engineering should be theorized across international and national platforms. Thus, women's under-representation in engineering is wellthought-out to be generally, the consequences of underlying preconception of the commonstructure of the Science, Engineering, Technology and Mathematics (STEM) (Noonan, 2017; Kristyn, 2019). Though, this perspective is deeply-rooted in Feminist point of view where established knowledge-driven situation are seen differently, as opinions are more superior than others(Reilly et al., 2016). This philosophy can be uphold in an organized society rooted in patriarchal system by race, class, and gender with partiality and domination perspectives. Thus, women's dominatedplace offers them anoutlooknot the same from and more broad that of males and Engineering as well as Science fields incorporate stereotypical malebeliefs, practices, and philosophies as a result of their past, practitioner, and settings(Metcalf, 2007; NSF, 2019). As many more women than their male counterparts repelincoming SET/engineering and give up their dreams of becoming an engineer so easily(Steinke et al., 2016; Van Oosten et al., 2017).

Revised Manuscript Received on October 25, 2020.

* Correspondence Author

Dr. Kehdinga George Fomunyam*, Institute for Systems Science, Durban University of Technology, Durban, South Africa.

(c) The Authors. Published by Blue Eyes Intelligence Engineering and Sciences Publication (BEIESP). This is an open access article under the CC BY-NC-ND license (http://creativecommons.org/licenses/by-nc-nd/4.0/)
The significant implications for women who opt for engineering possibly willgo through opposition concerning sex uniqueness along with male tradition of Science, Engineering and Technology (SET) and engineering profession (Barr, 2014; Anderson et al., 2018). This explains the radical interpretation of gender inequity in engineering, by means of associating with little challenging high-tech or science subjects. This perspective addresses the failure of liberal programme that do not reflect changes as women are seen resisting engineering field for unknown reasons rather misconceptions about such disciplines. Efforts endorsed in challenging women's under-representation in SET and its objection to gender role of socialization thwarts gender development (Chandler, 2012; Kaspura, 2014; Neumann et al., 2016). Curriculum and educationaldeviations as well as preparation can lead to intensificationof consciousness of SET teaching staff. Gender-based sensitive curriculum should be design to appeal women, which should be made of humanistic and socially oriented courses, that are flexible in course options, communication abilities and technology valuation, combined with antiquity of engineering (Yoder, 2012; Yang, 2016; Yoder, 2018). Hence, this paper presents a systematic review methodology which explore women as canons in engineering as well as theorizing their experiences and exploits in Africa.The systematic review method adopted in this paper identifies and appraise published articles from year 2009 to 2020 in fields of Engineering, History, Education, and Sociology, systematically. This was to appraise published reviews on study objectives and to discuss its implications with recommendations. The overall aim of this study is to fill the research gap by contributing to the overall understanding of theorizing experiences and exploits of women as canons in engineering in Africa. Specifically, we explore how women have made huge contributions in engineering fields; and how their exploits and experiences can be showcased in engineering, hence recommendations were advocated.

\section{THE RESEARCH GAP}

Women in engineering have made a lot of contributions in engineering sectors as their significant efforts are needed to address quality gaps and inspire younger generation of women to opt for engineering education. Thus, the number of women enlisted into various engineering disciplines has grown over the past years, yet engineering have been predominantly male (Bendemra, 2019; Bielefeldt, 2018; NSF, 2019). This gender imbalance has caused skill gaps and reduction of women in engineering.

Published By:

Blue Eyes Intelligence Engineering

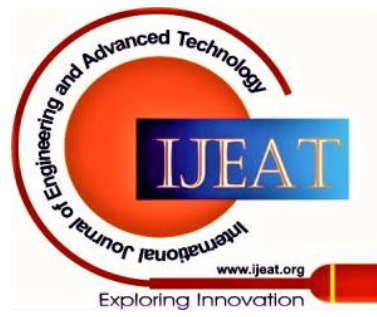


Thus, gender gap does not only remain but is growing actually, as trend of gender inequality and gender disparity persist, will continue to decrease the number of women engineers in the labour market in the near future. Therefore, an increased emphasis on gender equality would result in having more women in engineering disciplines(Franzway et al., 2009; EIGE, 2017; Daley, 2019). Despite the growing emphasis on gender equality, the gender disparity in engineering fields remains an issue in 21st century and in the fourth industrial revolution era. As technology advances at a rapid speed with an evolving labour market, an increasing number of engineering tasks requires skills and knowledge acquisition. Yet, there is a growing concern in theorizing experiences and exploits among women engineers, with a worrying contemplation, as 4IR debate on women's huge contributions in engineering sector cannot be reclusive from wider engineering platforms in Africa.

Hence, there is a clear discrepancy and a wide gap among male and female engineers, associated with sidelining in engineering fields. Still, women are still prima under-represented and marginalized in engineering, as women represent nearly $50 \%$ of market for workers, no more than $28 \%$ of females are found in engaging in STEM fields compared with their male counter parts (72\%). Globally and in Africa, engineering gaps keep increasing, and fewer women in comparison with men are choosing engineering degrees and jobs. The fact remains, regardless of the positive trend of women engineers, it is much rising number of recruited men than the number of females in engineering discipline; hence the crux of this paper. understanding of theorizing women's experiences and exploits as canons in engineering in Africa? How has women made huge contributions in engineering fields? What can be done to showcase women's exploits and experiences in engineering fields? What can be done to address the gaps in order to theorize the experiences and exploits of women in engineering? What are the recommendations in addressing these gaps in women in engineering in Africa? The answer to these questions are critical, urgent and unavoidable by all stakeholders within or outside engineering institutes, hence recommendations were advocated.

\section{METHODOLOGICAL APPROACH}

Systematic review of published academic sources was investigated as the author derived an expressed appraisal of objectives, categorize significant articles from sampled studies that meets the enclosure conditions, and evaluated the values of the sampled studies, as well as an abridged of the indication of an unequivocal approach(Gough et al., 2017). Based on the study objectives, significant research papers have been known across reviewed articles archive. The descriptors "women in engineering", "women as canons in engineering", "women's experiences and exploits in engineering", and "theorizing women's experiences and exploits" remain the key bases. The categorization permutation of the search themes such as "global", "USA", "developed countries", "developing countries" and "Africa", are all under-stated factors in women under-representation
The critical questions are: what is the overall

and marginalization in engineering sector (Borrego et al., 2015). Several papers (InêsDoreito et al., 2019) remained known by means of prospective sources of information, however, quality research papers that met the enclosure criteria were evaluated: (1) in printfrom2009 and 2020; (2) explored how women have made huge contributions in engineering fields in Africa as one of the lenses for analysis; and (3) examined to showcase their exploits and women encounters in engineering fields in Africa. Again, the papers were allocated into sub-sections relating to study objectives and identified types of analytical themes in sampled articles were itemized. In total, there were 76 reviewed articles indicating systematic review articles. Of those articles, only 66 articles clearly that were identified with the theme 'women as canons in engineering by theorizing their experiences and exploits in Africa' were used. The other ten articles simply specified more of 'logical theoretical papers'.

To recap the validation found in these sampled articles, appraisal of the sampled articles was completed, along with a developed coding sheet. These identified grouping on the coding sheet involve study's objectives, research questions, methods, type of data collected, study population, and relevant findings. Also, methods used to evaluate and review published articles scientifically, were drawn from existing studies (Gough et al., 2017; TorresCarrion et al., 2018;). This was followed by adopting logical research practices and reporting of systematic reviews were explained explicitly. After review, the principal investigator created the preliminary findings and patterns recorded in summaries. The author reviewed these summaries and initial outcomes to guide the concluding appraisal.

The principal investigator established the typical sampling framework involving articles that were analysed, in which the articles were used to outlined the study objectives. These illustrative samples were not taken wordperfect, but somewhatmade to explainexactly how analytical study on women in engineering be able to re-frame to redefine key themes and research questions in theorizing experiences and exploits in women engineers, as indicated byBrown et al. (2015). In addition, identifying and appraising process of published reviews allows researchers to describe the quality of compiled existing studies, summarize and compare the conclusions of the reviews as well as discussing the implications and recommendations of the reviews (Gough et al., 2017). The principles of systematic review methodology were emphasized in the studies to explore how women has made huge contributions in engineering and showcasing their exploits and experiences among women engineering that will primarily address the gaps in engineering education in Africa (TorresCarrion et al., 2018). Within the discussion part, we illustrated how we outlined thedescriptive studyobjectives presented amid the reviews emphasized by the studies analysed.

Published By:

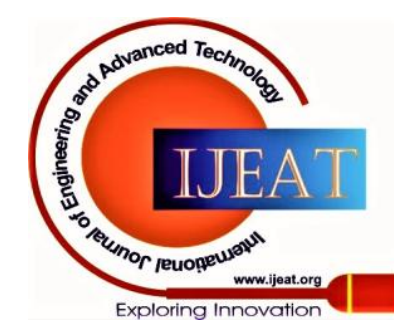




\section{LIMITATIONS}

Though this study focused on published articles in relation to the overall understanding of theorizing experiences and exploits of women as canons in engineering in Africa, there is possibility that principal investigators may have leave out significant research papers, perhaps taken into accountof women as canons in engineering within social contexts of research areas. Furthermore, it is documented that by selecting publications from 2009 to 2020, the principal investigator may have omitted earlier studies that have discuss women as canons in engineering in Africa by theorizing their experiences and exploits in Africa. Conversely, the emphasis of this paper was to study the contemporary studies on women as canons in engineering. Lastly, we want to concede that specific reviewed articles utilize rational hypotheticalcontext. On the other hand, applying the exclusion research objectives' principles, we concentrated on reviewed articles that applied no less than one logical context and did not analyse the effect of the addition of the research outlines applied.

\section{LITERATURE REVIEW}

The Sustainable Development Goals (SDGs) with an emphasis on SDG 5 - gender equality was incorporated in committees for women in engineering as one of the strategic themes is to overlay the significance on each SDG to highlight the importance of females in engineering can contribute to the achievement of each goal. This cannot be achieved with quality data availability on the proportion of women disqualified from working in engineering sector or gaining professional status as registered engineers, on global level (NAE, 2011; NRC and NAE, 2014; NSB, 2016 ). Therefore, there is an increased need for statistical data and highlighted gaps in data quality, geared towards achieving SDGs in addressing gaps in women engineering. In year 2020, women engineering organization has advocated for women engineers across various continents the opportunity for knowledge sharing across all disciplines of engineering, by orienting women engineers for better professional delivery (Adams, 2014; AAUW, 2015; Buse, 2018; Bruton, 2020b). This has led to recognition of the importance of women engineers in society as global technology world was realized that without the contributions of engineers, rapid development will not take place. Women engineers have a greater opportunity to showcase their performance, which will create an opportunity for the world to see women engineers are contributing actors to nations' development. Thus, in order to achieve gender equality, women should have a right to basic amenities, and not be made to subjugation practices (Dutta, 2015; EIGE, 2017). Gender equality is not only an underlying human right but a requisite basis for a nonbelligerent, flourish and sustainable world. One of the rationality for women representation as researchers are unclear, but may be linked with explanations that lie in the increasingprominence on nutrition security and industry as women were highly represented in Biotechnology (Fouad et al, 2016; Emelianova et al., 2019). For instance in southern Africa region, women were extremely under-represented in engineering fields $(16 \%)$ in 2004 and in an 'acceptedsystematicjobs' (16\%) in 2006, merely amount to $52 \%$ of personnelemployed in biotechnology-related companies. Likewise, in Israel, about $28 \%$ of senior academia were females, which revealed the trends that women were consistently relegated in engineering (14\%), physical sciences (11\%), mathematics and computer sciences (10\%), but with prevailing rates in education (52\%) and paramedical occupations (63\%) (Adams, 2014; Bendemra, 2019; Madgavkar et al., 2019). In Japan and the Republic of Korea, the proportion of females signifyabout $5 \%$ to $10 \%$ of engineering profession, as both countries showed a comprehensive gaps in net income between male and female researchers of the Organization for Economic Cooperation and Development affiliations, viz. 29\% for Japan and 39\% for the Republic of Korea (OECD, 2019). In Europe and North America, the proportion ofwomen who are former students in engineering, physics, mathematics and computer science is by and largehaving low participation rate. In developed nations such as in Canada, Germany and the USA, women make up about $19 \%$ of engineers and $22 \%$ of women engineers in Finland. Although, there are some vital studies that showed that $50 \%$ of engineering female graduates are in in Cyprus, 38\% in Denmark besides 36\% in the Russian Federation as well as in the case of New Zealand is equallydistinctive(Bendemra, 2019; NSF, 2019). Here, women from New Zealand increased from signifying 39\% to $70 \%$ of agrarianfemale graduates in 2000 and 2012, remained to dominate health (80-78\%) however yielded base in science (43-39\%) and engineering (33-27\%) (Adams, 2014). Importantly, a significant proportion of female engineers were observed within a number of emerging nations. For instance, out of ten, three were women engineers in Costa Rica, Vietnam and the United Arab Emirates (31\%), Algeria (32\%), Mozambique (34\%), Tunisia (41\%) and Brunei Darussalam (42\%). Besides, the statistics is even stupefying as $50 \%$ and $53 \%$ were recorded for Malaysia and Oman respectively. In African countries, reporting data revealed that about seven nations have detectedsignificantgrowths (more than 5\%) in women engineers in year 2000: Benin, Burundi, Eritrea, Ethiopia, Madagascar, Mozambique and Namibia (Corbett et al., 2015; Excell, 2017). Notably, four countries out of the seven Arab countries coverage data observe an increase in high percentage of women engineering students in the Arab countries. Thus, government has taken the urgency to improve a knowledge-based and flexible economy, having acknowledged the necessity for a resilient socialmeans based in engineering careers. For engineering learning institutions to promote women's enrolment into engineering programmes, requires the institutions to lay more emphases on the value of women's recruitment, the significance of engineering, financial aid support, and creating new efficient and easiest structural recruitment programme for women (Singh et al., 2013; Rosser, 2014).

Published By:

Blue Eyes Intelligence Engineering

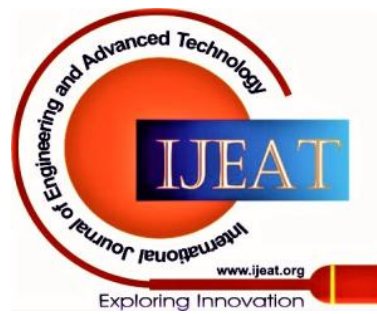




\section{Women as Canons in Engineering: Theorizing their Experiences and Exploits}

\section{Exploring women that has made huge contributions in Engineering}

Globally and in Africa, several campaigners and activist groups have made a lot of attempt to decrease gender disparity between male and female engineers and advocated for more recruitment of women into engineering programmes and workforce respectively. One of the strategies employed in the campaigns was to increase awareness of engineering courses during high school, by cultivating positivism idea in relating gender to engineering beliefs and generating a more female-friendly teaching and learning atmosphere(RAE, 2020). This have helped learning engineering institutions to encourage more females to sign up in engineering programme as well as other engineeringbased majors. In 21st century and fourth industrial revolution era, women are significantly under-represented in engineering disciplines, adding up to $10-20 \%$ of the engineering labour force globally. International and national organizations have clamour for programmes that will inspirefemales to engage in engineering studies as women engineers will be retained in the profession, supporting women to achieve their career goals(NSF, 2017; 2019). The global statistics that represent women researchers has masked wide intra-regional variations as studies have documented that $52 \%$ of female researchers are in Philippines and Thailand, thus with a parity in Malaysia and Vietnam. While in nations such as Indonesia and Singapore, only one in three females is a researcher.Studies also showed that few women are characterized as high researcher densities (15\%) and technological sophistication (18\%) respectively, which have shown great disparities from one region to another (Buse et al., 2013; Bruton et al., 2020a). However, in Southeast Europe, female researchers have anequality experiences; while $44 \%$ of women have been documented to be on the verge of gender parityin Central Asia and Latin America as well as in the Caribbean. Conversely, one out of three (33\%) female researchers in European Union, equated to $37 \%$ in the Arab world. Besides, female researchers werewellcharacterized in Africa (30\%) than in South Asia (17\%) respectively (UNESCO, 2019). Yet, women are under-represented in Science, Engineering, and Technology (SET) fields in university in developed and developing countries. Studies revealed that out of 31,205 undergraduates who opt to study science, engineering, and technology in Scottish university accounted for only 32\% of women in 1995 to 1996; and this extended from 14\% in Engineering and Technology to 62\% in Biological Sciences (UNESCO, 2019). The statistical illustration were more or less akin to the figures showing for the United Kingdom asunabridged, as well as the underrepresentation of female in most SET subjects perseveres in several other European countries, the United States, Canada, and Australia (Bendemra, 2019). Although, in the early 1980s a lot of national and international efforts have been made to explain this under-representation of females in SET subjects. These efforts had a specific aim that was to investigate and examine a broad scope of national and globalstudies, and to generatebenchmarks that are suitable practices in revealing female's right of entry to, contribution, along withdevelopment due to courses and careers in SET in colleges and university(Kristyn, 2019).
Building and achieving a more sustainable world require more women entering engineering profession. Thus, femaleare under-represented in engineering, hitherto they are required to improvecomprehensive solutions to address issues affecting engineering workforce. In African countries, a large proportion of women documented provide more than manual labour, as they are better placed in providing gender-responsive insights (UNESCO, 2019). Therefore, more females in engineering would stand as a role models for the future peers that will enhance nations economic growth and development. Engineering profession is a critical career path that will aid in achieving global sustainable development goals by 2030, and the vitalaim is fairness, as engineering career path must become as different as possible (UNESCO, 2019; NSF, 2019). Supporting more women in engineering workforce, will be beneficial, which increases the prospective to growan allencompassing, and ground-breaking solutions to address world multifaceteddifficulties.

\section{Seeking to showcase Women exploits and experiences in Engineering}

Historically and presently, women are devalued in academic and professional engineering disciplines, asa lot ofwomen contribute to the various engineering disciplines A lot of national and international organizations and programmes have been put in place to understand and surmount the tradition of gender inequality. Studies have cited that gender inequality has created gender gap, which indicates the absence of potential talent (Bruton et al., 2020a)'Thus, there is a growing gap of women entering engineering academia and workforce.Factors such as gender stereotypes, low proportions of woman engineering students, and engineering principles contribute to the contemporary position where male dominate engineering field. In ages of the 20th era, limited number offemales were permitted to applied to engineering university programmes and were regarded with wonder by their male colleagues. History revealed that in 1904, Maria Elisabeth Bes graduated in chemical engineering from the Polytechische School te Delft, becoming the first female graduate engineer in the Netherlands (White, 2018) WhileNora Stanton Blatch Barney (1883-1971), was the first female to obtained civil engineering degree from Cornell University in 1905 and was accepted as a junior fellow of the American Society of Civil Engineers in the same year.However, her demand in lieu of promotion to associate affiliation was denied, after worked as an engineer, architect, and engineering inspector for twelve years (Powell et al., 2009; 2011; 2015). Also, Olive Dennis (1885-1957) became the second female to graduate from Cornell university with civil engineering degree in 1920, and was initially hired by the Baltimore and Ohio Railroad as a draftsman and shortly, turn out to be the first female to claim the Service title of Engineer when the title was initiated(Rees, 2019). Besides, Cleone Benest passed the City and Guilds of London Institute's motor-engineering examination, and the
Published By:
Blue Eyes Intelligence Engineering and Sciences Publication

(C) Copyright: All rights reserved.

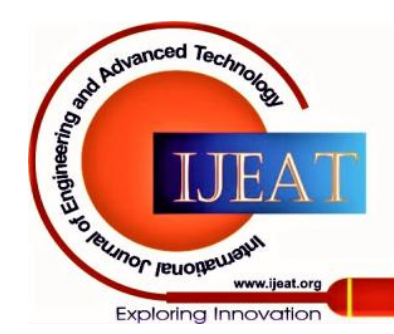


Royal Automobile Club's mechanical test in 1908 and later, took the Portsmouth Municipal College examination for heat engines in 1910. Using the professional name of C. Griff, she joined numerous engineering establishments and started a consultancy business in Mayfair(Rees, 2020).As well, Alice Perry of Europe was one of the first officially recognized woman engineer,whoproceeded with engineering degree in 1908 from Queen's College, Galway. Likewise, Emma Strada was the first female engineering graduate in Italy, coming 3rd out of 62 persons in her class in 1908. Alike, Elisa Leonida Zamfirescu (1887-1973) was rejected by the School of Bridges and Roads in Bucharest, Romania due to bias against women in the sciences. Shortly at the Royal Academy of Technology in Berlin in 1909, she was accepted and later graduated from the university in 1912, with an engineering degree by specializing in chemistry.Perhaps, she became one of the first female engineers in the world (SWEB, 2017).Moreover, Edith Clarke, an architect of graphical calculator, was the first female to receive MIT's electrical engineering degree in the department in 1918. Sheturn out to be the first female admitted to the American Institute of Electrical Engineers, the predecessor to the IEEE, and later, taught at the University of Texas Austin, where she was the only female faculty member in the engineering department (UNESC0, 2019). The first engineering society for females named Women's Engineering Society (WES) was founded in 1919 in the United Kingdom and is still dynamic in continuing to support women engineers till present day (Peers, 2018). The founders include Lady Katharine Parsons, who was involved with her husband, Sir Charles Parsons in the engineering work, their daughter plus the first President of WES Rachel Parsons, house builder and suffragette, Laura Annie Willson, Eleanor Shelley-Rolls, Margaret Rowbotham, Margaret, Lady Moir, with Caroline Haslett the founding Secretary. Furthermore, in 1920, Juana Pereyrawas an alumna of the Engineering Faculty of the Universidad de la República in Uruguay, with the title of Ingeniera de Puentesy Caminos (Engineer of Bridges and Roads), making her one of the first female engineers in South America (Stanley, 1993; Bruton et al., 2020). In 1921, Sébastienne Guyot (1894-1941) graduated in mechanics and engineering in the first year groupinthe Central School of Parisinpermitting female undergraduates' participation, and turn out to be an aeronautical engineer, while ending her career as the Head of the Helicopter Service at the French Arsenal de l'Aéronautique(Bendemra, 2019). Thus, Marguerite Massartis an alumna from the Université Libre de Bruxelles with civil engineering degree, making her to qualify as the first female engineer in Belgium in 1922. Later in Ghent, she set up a thrivingcommercial factory, where she presented a 'desalinisation project' as well as early solar panels in the first hotel on Sal Island in Cape Verde(Bruton et al., 2020). Likewise, the first female to earn a degree incivil engineering in Mexico was Concepción Mendizábal Mendoza in 1930. Similarly, Ying Hsi Yuan trained as a Civil Engineer in Peiping in the 1930s and worked in bridge design in China before taking a postgraduate study in engineering from theUniversity of Liverpool in the 1940s. Later, she was working in Hong Kong after completing her postgraduate study(SWEB,
2017). The Polish electrical engineer Maria Wanda Jastrzębska earned a master's degree in electronics and constructed an early computer labs which brought aninspiration into the university teaching in 1952. Also, Araceli Sánchez Urquijo became the first civil engineering woman to join the workforce in Spain, having been among the first 45 hydropower engineers trained at the Moscow Power Engineering Institute in 1952. PremalaSivaprakasapillaiSivasegaram studied Engineering at Somerville College, Oxford in the 1960s and became the first female engineer of Sri Lanka. In the 1970s, Margaret Hamilton wasknown as a renowned computer and aerospace engineering contributor and the head of Software Engineering Division of the MIT Instrumentation Laboratory. At that point, she is well-known for her efforts she puts into writing the on-board guidance code for the Apollo 11 mission (White, 2018). Notwithstanding, Ada Lovelace aged 17 years met Charles Babbage in 1832 where Charles Babbage demonstrated his plans to her of wanting to create an 'Analytical Engine'(Bendemra, 2019)). Lovelace began by accumulating the pages of notes and her thoughts to his paper and wrote an algorithm programme with a computer machine to create numbers in the Bernoulli series.Charles Babbage circulated these Ada Lovelace's memorandum along with his paper explaining his 'Analytical Engine'.However, not more than a century after her death, Lovelace's memorandum were presented as the global first computer programme Besides, Edward Charles Pickering was an astrophysicist and director of the Harvard College Observatory. He gave paid work to females to form a group titled 'computers', in order to examine the collected stars data for his study(UNESCO, 2019). This group of females were carefully chosen for many purposes, first, as they get half payment for work than the male counterparts. Thus, documenting stars was tedious and difficult as there were many stars, and securing more persons for idem monetary value was profitable. Second, the university teacher who is accountable for the research would be less intimidated by a woman, as young adult males might get their viewpoints to contend in order to have their names written on published documents. In late year 1800 to early 1900, women were hardly permitted to study science disciplines or take recognition for pioneeringinnovations, or 'work at large', were named after Pickering or Harvard (Bruton et al., 2020a). Despite the awe-inspiring innovations that would ultimately be approved to these females, hence, the group was disgustingly speak of as Pickering's Harem. Likewise, in 1923, Cecilia Payne-Gaposchkin, as a female was prohibited to study science in Great Britain. She had to exitedthe country and relocated to study Harvard computer science. Interestingly, she was amazed by the compassion among the company of other females and this group influenced the emergence of contemporary astrophysics (Powell et al., 2015). Her breakthrough was to figure out what stars were made of, in discovering a new paradigm shift, that led to her thesis writing which was rejected. Thereby,

Published By:
Published By: and Sciences Publication

(C) Copyright: All rights reserved.

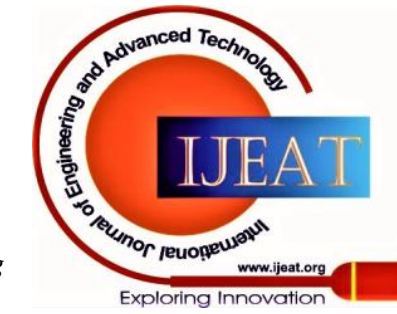

Exploring Innovation 
having her fold to agreement in waiting for four years until they figured out she was right at the entire time. Her stellar atmospheres thesis become the standard text in the field and is still held as one of the most highly regarded publishedarticles ever written in astrophysics. Presently, having the understanding of what stars are made of, the measuring distances in spaces methods used and the categorization of stars can all be attributed to the Pickering's femalegroups(White, 2018). Similarly, Henrietta Swan Leavitt providedthe support basisofthe connection in the combination with radiance and the Cepheid variable. Thus, this hasinfluencedcontemporary understanding of the universe magnitude and distances in an interval of time beingmeasured (Rees, 2019). However, Antonia Maury adapted the way stars are classified, and Annie Jump Cannon modified it again in 1912. This method of classifying starts is being used till this present times, as this research was combined with the cataloguing of over onefourth of a million stars in Cannon's existence. Notably, with the discrimination of being female participating in science, both Cannon and Leavitt had hearing-impaired incapacity, illustrating that handicapped individuals have created an outstanding contributions to science as well (Rees, 2020). In 1953, Katherine Johnson, is one of the African-American women 'computers', who joined the Department of Guidance and Navigation for the National Advisory Committee for Aeronautics (White, 2018). Right at that point, she incessantly accomplishedestimations on inbound records using the black boxes of airplanes. Shefinally moved on to become an aerospace technologist, designing inbuilt part of the Spacecraft Controls Branch where she calculated the trajectories of spacecraft and return-flights directions. Thus in 2015, she was accolade with the Presidential Medal of Freedom, which is the America's highest civilian honourfor her many roles played in STEM. Notably in 2016, a movie showing relating to Katherine Johnson and her accomplishments with the title 'Hidden Figures' created front-page(SWEB, 2017). Hedy Lamarr may remain being the best and well-known for her performing acts career, as several people do not have a prior knowledge that she was also a brilliant inventor (Powell et al., 2015). When working with composer George Anthell, they used a frequency hopping spread spectrum to prevent radio guidance systems from being jammed in WWII. Till this present day, thesame technology is being used for WiFi, Bluetooth, and similar technologies. Fourteen years after her death, Hedy Lamarr was not inducted into the National Inventors Hall of Fame, as she live between 1914 to 2000. In addition, Stephanie Kwolek was a female engineers who learntabout the bulletproof fibre Kevlar, presently protecting soldiers worldwide, as well as Josephine Cochrane invented the dishwasher (Daley, 2019). Thus, several femaleshave been ignored for patents rights and prizes in favour of their supervisors, and still, their contributions have distorted the world and lives within it. Aside, supporting female engineers with strong abilities and capacity development, will motivate women in engineering not only as professionals but working towards an outstanding allied social unit in future developing activities of the country (Warren et al., 2016).

\section{Factors contributing to low female participation in engineering}

There are various factors that contribute to lower participation and under-representation in engineering academia and workforce. Some of these underlying factors are as follows:

1. Gender stereotypes: this menace may contribute to inadequately representation of female engineers as engineering disciplines are traditionally seen as a malecontrolled field, as females may possibly be less assertive about their capabilities, even when performing equally (O'Brien et al., 2015). A significant evidence has shown that an implicit bias has been placed against women engineers as menfolk see themselves as arithmetically higher and better suited to engineering tasks.Also, self-valueis related to sex roles since males have habitually pose higher self-worth compared to females. This has affected women in wanting to opt to or not to choose engineering major (Jones et al., 2013)

2. Subordination of womenundergraduates in degree programmes in engineering: Degree inequalitydiffers across engineering subjects or fields of activities as females are generally inclined to be more captivated in engineering fields with social and humanistic education, such as agronomic and ecological engineering(Morganson et al., 2010). Females are treated indifferently in collaboration research group, especially when there are more male than female,hence, male colleagues will exclude females from the real engineering work. However, in academia, professors have been described how female students are being treated differently, simply because they were just women. This aspect in academia makes the rates problematic to become larger as females are judged as less experienced than males to execute supposedly 'masculine tasks'.

3. Engineering Culture: Another affirmative explanation for low female involvement in engineering disciplines is the preponderance of belief connected with masculine role in place of employment culture (RAE, 2020). For instance, female engineers have find it challenging to return to place of employment after an interval of time of non-attendance in workplace, as assumptions were since males are less likely to take time to look after their family and as a result of that, this inexplicably affects women.Thus, men are also connected with taking leadership roles in place of employment as they hold higher position of power over women, in which they may create an awkward environment for female engineers. Such scenarios may include women, perhaps,been given lower wages, more tasks, or less indebtedness as compared with the males(SCS, 2019). On the other hand, females possibly will have added abilities to turn out to be a virtuous leaders as they may have more key leadership skills, with strong aptitude to inspire employees, build relationships, and gain upper hand.

4. Communication: Also, communication is a causative factor used to split males and females in place of employment. For a man to man social interaction is said to be more direct than women, as men clarifies a task to their female counterparts,

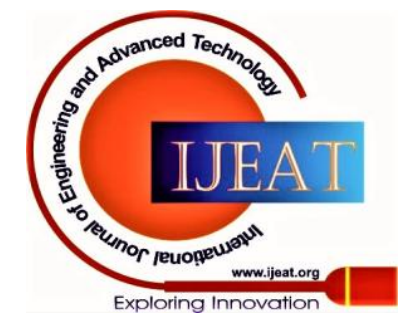


likely to use 'talk down' or 'dumb down' tactics (Funk et al., 2018). This comes from a stereotype that men are more qualified than women, and can drive males to treat females as subordinates in place of contemporaries.

\section{THEORETICAL FRAMEWORK}

This paper was guided by Liberal Feminism, one of the varieties of contemporary Feminist Theory. Liberal Feminist theory was adopted from a keymanifestation of gender inequality theory, which argues that women may claim equality with men on the root of an crucial human ability for rationalethicalintervention, that gender disparity is the consequence of a sexist imitating of the splitting up of workforce, and that gender equality can be formed by altering the detachment of workforcethrough the repatterning of significantorganisations(Schaeffer, 2001). Thus, men and women are positioned in the public not only contrarily but also inequitably. Women get less of material resource, social status, power,and prospects for selfactualization than men do who share their position, be it a position based on class, race, occupation, ethnicity, religion, education, nationality, or any intersection of these aspects(Schaeffer, 2001). This theory can be applied to show the gender gaps and under-representation of women in engineering in order to explore and celebrate the societalworth of female's uniquemeans of being, that is, of the ways in which female are different from males. However, changing attitudes is an important component in closing gender gap in engineering. As male-dominated industry, which have push for change in helping women with rewarding career satisfaction. Even though, engineering discipline is tagged as 'masculine', yet successful women have made ground breaking records in engineering sector (Cheryan et al., 2015). Presently, even with countable impediments for women in engineering, women are beginning to have career satisfaction and job rewarding from their career choice. Engineering sector still have a role to play by addressing the diversity issues which is key in closing skills gaps. One of the ways to do that is to inspire young girls from their tender age around the creativity aspect of engineering, and which is important in enlisting more women to the sector (Christidou et al., 2016). Nonetheless, sustained efforts are needed to persuade women to pursue engineering careers, which will stimulate advancement and impact of engineering industries. These changing attitude will help in closing gender gap and gender inequality in engineering. Nevertheless, Liberal Feminist pursue change through law, legislation, litigation, and regulation and through petition to the human ability for reasoned moral judgments, or the capacity of the public to be moved by arguments for fairness (Risman, 2004; Martin, 2004). They argue for equal educational and economic projections, equal family life responsibility; the elimination of sexist messages in family, education, and mass media and individual encounters to sexism in daily life (Lorber, 1994; Risman, 2004). Changes in teaching and learning strategies which include adoption of holistic, participation, and gender-inclusive conceptualization which can engender ownership of learning and building self-assurance in engineering students. There are explicitapproaches that may include extending the array of teaching and learning methods, inspiring students' interaction, teaching teamwork skills, and making more obviousassociations between hypothetical and practical learning (Excell, 2017). Also, there are institutions that are currently committed resources to gender fairness training that will address the issue of gender equity in engineering classroom (Isaac et al., 2009). To address gender issues in engineering, engineering educators can raise gender- sensitivity among diverse engineering student, which will help to create a conducive classroom to learning. The robust theoretical understanding of gender and engineering are sophisticated as the approach employed to address the problem of women's underrepresentation can incorporate better gender policies.

\section{DISCUSSION}

History has it that female engineers have generated greatest accomplishments in engineering fields even though, gender inequalities have consistently thrive in various forms in 4IR era. Thus, women in engineering fields do not have equal position and status with their male counterparts, but preferably to bring the fact that females come amidst different, and frequently, more thought-provoking obstacles along their career path than men (SCS, 2019; UNESCO, 2019). The multiplicity throughout long history of Science and Engineering have pointed out that females are still facing many challenges today in engineering industries. In order to advance Engineering disciplines, relevant stakeholder both at the national and international levels must recognize gender inequality in engineering workforce and ways to overcome these biases (Yoder, 2018; RAE, 2020).

In the year 1960 , women only made up around $1 \%$ of the engineering workforce, although, times have changed and the disparity between males and females is changing for the better (OECD, 2019; SCS, 2019). The global statistics figures of female engineering workers revealed the percentage of women engineers in selected developed countries including: Lithuania 106, 200 (57.0\%), Norway 315, 800 (54.7\%), Latvia 51,400 (52.3\%), Bulgaria 207,900 (51.9\%), Denmark 300.200 (50.7\%), Portugal 392.600 (49.9\%), Poland 1,252,900 (48.7\%), Ireland 247,000 (48.7\%), Spain 1,425,900 (48.4\%), Sweden 614,600 (48.4\%), and United Kingdom 3,578.600 (40.8\%)(OECD, 2019; UNESCO, 2019). It is important to have knowledge that climate, environmental and basic social amenities are all representing present-day challenges with high demand of engineers. Thus, Emirati female engineering have indicated a strong attraction for an engineeringprofession for reasons of economic independence, high social prestige associated with engineering profession and the prospect to engage in creative and challenging task with a comprehensivevariety of career prospects(Bielefeldt, 2018; Bendemra, 2019). Notwithstanding, Arab women engineers are still plagued with barriers in finding gainful employment after graduation, as these obstacles include a misalignment between university programmes and labour market demand, lack of career awareness in selected field,
Plue Eyes Intelligence Engineering and Sciences Publication

(C) Copyright: All rights reserved.

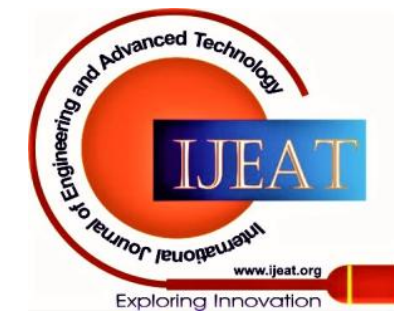


and family prejudicecontrary to working in mixed-gender environments as well as dearth of women role models.

Similarly, in Malaysian, engineering industries is made up equal number of males and females employees, as large number of females are employed as university teachers and in the private engineering sector (Christidou et al., 2016). This was possible as families tend to be reassuring of their female children's entry into prominent and greatlyrewarded industry in the wellbeing of upward social flexibility. Likewise, in India, anextensive increase in women engineering students may be inferred as a change in the 'masculine' sensitivity of engineering and a product of interest on part of parents that their female children are guaranteed of employment as the field develops as well as expedientnuptial of their female wards (Kersley et al., 2019). Besides, in Myanmar, 42\% of female workers are found in doing engineering jobs as they are working for the country's politics, livelihood, social skills and other development jobs. In year 2013, the government of Myanmar launched the Women Engineers Chapter, Federation of Myanmar Engineering Societies (Fed.MES) to showcase performance of women engineers and mentoring the new generation of young women engineers to attain the position of an international standard engineers (UNESCo, 2019). Thus, the first Myanmar Women Engineers Summit was celebrated with the purpose of improving women engineering standard, to cooperate more effectively among women engineers in order to develop a new generation of women engineers. Still, women were found making up just $8 \%$ to $10 \%$ of engineers in nations like in Kenya and South Africa, as such gender-responsive perception are probable to be incomprehensible (OECD, 2019; RAE, 2020). This inference can also be related to trends of gender inequality against women engineers in developed countries like Canada and New Zealand, where females in engineering remain to face underrepresentation in engineering place of employment, which is often accounted for less than a fifth of engineering labour force (OECD, 2019; UNESCO, 2019). It is important to indicate that recruiting more women engineers can advance the strategy of new products and solutions to benefit both men and women. Female engineers are required as role models to stimulate more female and male adolescents to study science and technology-based subjects, which raise a new cohorts of technical specialists(Adams 2014; Anderson et al., 2018). Presently, many countries globally are suffering from unavailability of engineering talents, often compounded by preconception that is holding back half of the possible workforce. There has been a lot of efforts put in place to increase gender balance in engineering education for better national policies, have helped to make a change. Countries such as Kuwait, females make up to $60 \%$ of engineering university undergraduates, yet many do not into labour force (Emelianova et al., 2019; OECD, 2019). Experiences of women engineers are never showcased to exhibit their enormous personal accomplishment on the job, as the context of engineering workforce is subjugated by men. This preconception can be daunting and has led fewer females dialogue their opinion or sharing their knowledge to a larger audience. For instance, in Italy, the number of female in engineering sector is gradually increasing, with the number of women engineering graduates rising from $16 \%$ at the turn of the century to $28 \%$ in 2017 . Simply, having more females in top positions will aid in giving conspicuousness to opportunities for women in engineering, by guaranteeing more justifiable, inclusive and representative executive decisions(Bielefeldt, 2018). Advocating committee on women in engineering is so significant for the recognition of women engineers' contribution in order to honour their achievements, which will give female engineers a global platform through consistent and systematicactions, devoted means and networks.

\section{Implications for Theorizing Women Experiences and} Exploits as Canons in Engineering

Research studies have explore a lot of suggestions that will create a supportive gender-balanced learning environments that will accommodate increasing number of women in engineering. This will provide better opportunities in developing women for leadership and building consciousness of prejudice through staff development and training (Blume-Kohout, 2014; Cociuban, 2015). With continued underrepresentation of female in engineering and the prevalent gender bias as well as gender inequality, interventions should be premeditated to assist women's representation and doggedness to increase anextensiveresponsiveness of parityconcerns in engineering fields and workforce (Van Oosten et al., 2017). This is very important as the positive experiences and exploits of women in engineering should be showcased in international and national networks to feature the success stories of female engineers, predominantly in engineering roles in Africa. The existence of women engineers will stimulate professional opportunities and career pathways for younger generation of young women who inspired to follow engineering career pathway (Blume-Kohout, 2014; Cociuban, 2015; Madgavkar et al., 2019; Morganson et al., 2010).

Thus, engineering workforce and professional sectors should re-strategize and critically build a wide range of identities involving informal and formal mentors that will teach women in engineering to handle gender gaps and gender inequality to reduce preconceptions and stereotypes. Beyond the implications for and responsibilities of engineering educators and professionals to make available a safe and supportive work atmosphere for female engineer in order to contribute their role in building nation's development and technology advancement (Rosser, 2014; RAE, 2020). International and national stakeholders must support and create structured systems that will implement established policies and communicate the policies expectations to engineering employers and engineering institutions regarding women's recruitment into engineering workforce (Bruton, 2020b). Further, engineering bodies must make available greater prospectaimed at female engineering students to provide feedback about their skills with engineering educators and employers, via a created consolidatedstructure or professionaldevelopment services to collect and ascertain issues as well as trends related to gender-based discrimination among female engineers in Africa.

Published By:

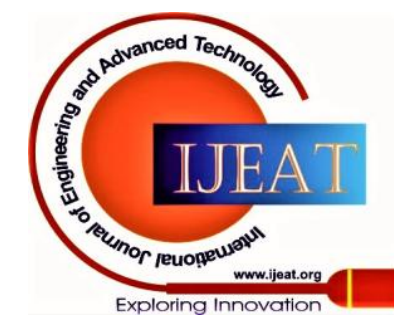




\section{CONCLUSION AND RECOMMENDATIONS}

This paper attempts to show that in Africa, the experiences and exploits of women as canons can be theorized in engineering, which is very imperative in addressing gender gaps and gender inequality among women engineers at different stages in their career. Thus, the importance of under-representation of women engineers may be linked to structural and cultural impediments within engineering settings. These barriers may negatively affect women as it will make them not to reach their full potentials. However, history of marginalization and gender gap of women engineers with engineering workforce are mostly dominated by men. In addition, indication to support females who work in male-controlled engineering disciplines will practice gendered barriers that do not only hinder their achievements, but also to make it challenging to preventdiscrimination in an engineering place of employment. The structural and cultural barriers to tenacity and overall success are receiving great consideration from relevant stakeholder but more efforts are needed to address the constrains women engineers faced. Studies have revealed a long history of women in engineering plagued with marginalization, isolation and subjected to stereotyping threat in engineering workforce. Differential attention and bias towards women in engineering will tend to have negative fundamentaland basic penalties for females' perception of their own capabilities. Thus, women's ideas are seen as less valued and unwelcomed in comparison to male counterparts in male-dominated engineering fields. Hence, closing the gender gap in engineering, is of critical importance in Africa as failure to address these concerns in women engineers will result to wider gender disparities and gender inequality in engineering. Therefore, key recommendations are advocated as follows:

1. Consistent with feminist view point, accounts of women engineers' expediencies and exploits should be documented to give vital insight into gender dynamics that will aid in implementing gender policies to address underrepresentation of female in engineering fields.

2. Sensitization programmes ought to be facilitated to increase awareness of gender gaps and gender inequality problems to decrease low participation and underrepresentation of female in engineering programmes, and to tacticallyaid women access, persistence, and success in women engineers' endeavors.

3. Recruitment and retaining of female engineers into engineering labor force should be a primary objective that is critical for gender equity and opportunity that will assist in meeting national goals and needs.

\section{REFERENCES}

1. Adams R (2014). 40 Percent Of Female Engineers Are Leaving The Field. This Might Be Why. Huffington Post.

2. American Association of University Women (AAUW), (2015) Solving the Equation: The Variables for Women's Success in Engineering and Computing. Washington, DC: AAUW.

3. Anderson DM, Baird MD, Bozick R (2018). Who Gets Counted as Part of America's STEM Workforce? The Implications of Different Classification Approaches for Understanding the Gender Gap in STEM (RAND Corporation Working Paper): Pp. 17-19.

4. Barr V (2014). Women in Stem, Women in Computer Science: we're Looking at it Incorrectly. Accessed on 20th of September, 2020 from http://cacm.acm.org/blogs/blogcacm/18085 0-women-in-stemwomen-in-computer-science-were-looking-atit-incorrectly/fulltext.

5. Bendemra H. (2019). Caught short: a snapshot of Australian engineering. The Conversation.

6. Bielefeldt AR (2018). Professional Social Responsibility in Engineering, Social Responsibility, Ingrid Muenstermann, IntechOpen. Accessed on September 25th, 2020 from: https://www.intec hopen.com/books/socialresponsibility/professional-social-responsibility-in-engineering.

7. Blume-Kohout M (2014). Understanding the gender gap in stem fields entrepreneurship. Small Business Assoc. Office Advocacy.

8. Borrego M, Froyd J, Foster M (2015). What is the State of the Art of Systematic Review in Engineering Education? Journal of Engineering Education; 104 (2): 212-242.

9. Brown PR, McCord RE, Matusovich HM, Kajfez RL (2015). The use of motivation theory in engineering education research: a systematic review of literature. European Journal of Engineering Education; 40 (2): 186-205.

10. Bruton E (2020b). Uncertain at Present for Women, but May Increase: Opportunities for Women in Wireless Telegraphy during the First World War. Information \& Culture; 55 (1): 51-74.

11. Bruton E, Mar H (2020a). A History of Women in British Telecommunications: Introducing a Special Issue. Information \& Culture; 55 (1): 1-9.

12. Buse K (2018). Editorial: Women's Under-representation in Engineering and Computing: Fresh Perspectives on a Complex Problem. Front. Psychol.; 9:595.

13. Buse K, Bilimoria D, Perelli S (2013). Why they stay: women persisting in US engineering careers. Career Development International; 18 (2): 139-154.

14. Carlana M (2019). Implicit Stereotypes: Evidence from Teachers' Gender Bias.The Quarterly Journal of Economics; 134 (3): 11631224.

15. Chandler MA (2012). Women at Forefront of Booming Forensic Science Field. Accessed on September 20th, 2020 from https://www.washingtonpost.com/lifestyle/magazine/wom eatforefront-of-booming-forensic-science field/2012/07/27/gJQAkASRPX_story.html.

16. Chemers MM, Zurbriggen EL, Syed M, Goza BK, Bearman S (2011). The role of efficacy and identity in science career commitment among underrepresented minority students. J. Soc. Issues 67: 469-491.

17. Cheryan S, Master A, Meltzoff AN (2015). Cultural stereotypes as gatekeepers: increasing girls' interest in computer science and engineering by diversifying stereotypes. Front. Psychol.; 6: 49.

18. Christidou V, Bonoti F, Kontopoulou A (2016). American and Greek children's visual images of scientists: enduring or fading stereotypes? Sci. Educ.; 25, 497-522.

19. Cociuban A (2015). Elisa Leonida Zamfirescu - First female engineer in the world. Amazing Romanians.

20. Corbett C, Hill C (2015). Solving the equation: the variables for women's success in engineering and computing. Am. Assoc. Univ. Women.

21. Daley LP (2019). Trend Brief: AI and Gender Bias; Sophia Ahn and Amelia Costigan, Trend Brief: How AI Reinforces Gender Stereotypes; Catalyst.

22. Dutta D (2015). Sustaining The Pipeline: Experiences Of International Female Engineers In U.S. Graduate Programs." Journal of Engineering Education 104 (3): 326-344.

23. Emelianova O, Milhomem C (2019). Women on Boards: 2019 Progress Report (MSCI): p. 15

24. European Institute for Gender Equality (EIGE), (2017). Economic Benefits of Gender Equality in the EU: How Gender Equality in STEM Education Leads to Economic Growth.

25. Excell J (2017). How big is the gender pay gap in UK engineering? The Engineer.

26. Fouad NA, Singh R, Cappaert K, Chang W-h, Wan M (2016). Comparison of women engineers who persist in or depart from engineering. J. Vocat. Behav.; 92, 79-93.

27. Fox M, Sonnert G, Nikiforova I (2011). Programs for Undergraduate Women in Science and Engineering: Issues, Problems, and Solutions. Gender \& Society. 25 (5): 591.

28. Franzway S, Sharp R, Mills JE, Gill J (2009). Engineering Ignorance: The Problem of Gender Equity in Engineering. Frontiers: A Journal of Women Studies. 30 (1): 90.

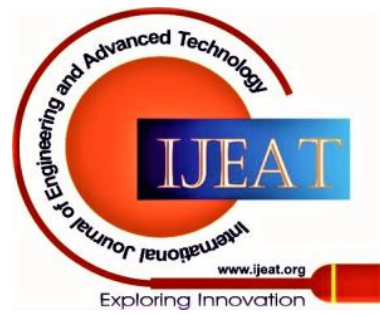


29. Frehill LM (2010). Satisfaction: why do people give up engineering? Surveys of men and women engineers tell an unexpected story. Mech. Eng.; 38-41.

30. Funk C, Parker K (2018). Women and Men in STEM Often at Odds Over Workplace Equity; Pew Research Center; Pp. 24-55.

31. Glass JL, Sassler S, Levitte Y, Michelmore KM (2013). What's so special about STEM? A comparison of women's retention in STEM and professional occupations. Soc. Forces; 92: 723-756.

32. Gough D, Oliver S, Thomas J (2017). An introduction to systematic reviews. London: SAGE.

33. Hewlett SA, Luce CB, Servon LJ, Sherbin L, Shiller P, Sosnovich E, et al. (2008). The Athena Factor: Reversing the Brain Drain in Science, Engineering, and Technology (Harvard Business Review Research Report). Boston, MA: Harvard Business Publishing.

34. InêsDoreito SC, Manish M (2019). The study of grit in engineering education research; a systematic literature review. European Journal of Engineering Education; Pp. 1-26. doi: 10.1080/03043797.2019.1688256.

35. Isaac C, Lee B, Carnes M (2009). Interventions that affect gender bias in hiring: a systematic review. Acad. Med.; 84: 1440-1446.

36. Jones BD, Ruff C, Paretti MC (2013). The impact of engineering identification and stereotypes on undergraduate women's achievement and persistence in engineering. Social Psychology of Education: an International Journal; 16 (3): 471-493.

37. Kaspura A (2014). The Engineering Profession: A Statistical Overview. Engineers Australia: 117.

38. Kersley R, Klerk E, Boussie A, Longworth BS, Natzkoff JA, Ramji D (2019). The CS Gender 3000 in 2019: The Changing Face of Companies; Credit Suisse Research Institute: p. 14-15.

39. Kristyn F (2019). A Gender Analysis of the Occupational Pathways of STEM Graduates in Canada (Statistics Canada, Analytical Studies Branch Research Paper Series); Holly Else, "Nearly Half of US Female Scientists Leave Full-Time Science After First Child," Nature.

40. Madgavkar A, Manyika J, Krishnan M, Ellingrud K, Yee L, Woetzel J, Chui M, Hunt V, Balakrishnan S (2019). The Future of Women at Work: Transitions in the Age of Automation; McKinsey Global Institute; p. 38-39.

41. Metcalf H (2007). Recruitment, Retention, and Diversity Discourse problematizing the "problem" of Women and Minorities in Science and Engineering. Master's thesis, University of Arizona, Tucson, AZ.

42. Morganson VJ, Jones MP, Major DA (2010). Understanding women's underrepresentation in science, technology, engineering, and mathematics: the role of social coping. Career Dev.; Q. 59: 169-179.

43. National Academy of Engineering (NAE), (2011).What is engineering and what do engineers do? National Academy of Engineering website FAQ.

44. National Research Council (NRC), National Academy of Engineering (NAE), (2014). Career Choices of Female Engineers: A Summary of a Workshop. Washington: The National Academies Press.

45. National Science Board (NSB), (2016). Science and Engineering Indicators 2016. Arlington, VA: National Science Foundation (NSB2016-1). Accessed on September 27th from https://nsf.gov/statistics/2016/nsb20161/uploads/1/nsb20161.pdf.

46. National Science Foundation (NSF), (2017). Women, Minorities, and Persons with Disabilities in Science and Engineering. Arlington, VA: National Science Foundation. Accessed on Sept ember 2020 from https://www.nsf.gov/statistics /wm pd/

47. National Science Foundation (NSF), (2019). Table 9.7: Employed Scientists and Engineers, by Ethnicity, Race, Occupation, Highest Degree Level, and Sex: 2017.Women, Minorities, and Persons with Disabilities in Science and Engineering, Data Tables.

48. Neumann MD, Latham SA, Fitzgerald-Riker M (2016). Resisting cultural expectations: Women remaining as civil and environment engineering majors. Journal of Women Minorities in Science and Engineering; 22: 139-58.

49. Noonan R (2017). Women in STEM: 2017 Update. US Department of Commerce, Economics and Statistics Administration, Office of the Chief Economist: p. 2.

50. O'Brien, L. T., Blodorn, A., Adams, G., Garcia, D. M., and Hammer, E. (2015). Ethnic variation in gender-STEM stereotypes and STEM participation: an intersectional approach. Cultur. Divers. Ethnic. Minor. Psychol.; 21: 169-180.

51. Organization for Economic Cooperation and Development (OECD), (2019). Why Don't More Girls Choose to Pursue a Science Career?PISA in Focus, No. 93.

52. Peers S (2018). Women in Engineering Statistics. Data and information on gender, diversity, STEM and engineering in particular. The Women's Engineering Society (WES) Statistics.
53. Powell A, Bagilhole B, Dainty A (2009). How women engineers do and undo gender: Consequences for gender equality. Gender, Work \& Organization; 16: 411-28

54. Powell A, Dainty A, Bagilhole B (2011). A poisoned chalice? Why UK women in engineering and technology students may receive more 'help' than their male peers. Gender and Education 23: 585-99.

55. Powell A, Sang KJC (2015). Everyday experiences of sexism in maledominated professions: A Bourdieusian perspective. Sociology; 49 919-36.

56. Rees E (2019). Who launched the Women's Engineering Society in 1919? Electrifying Women.

57. Rees E (2020). The Long Read: Discovering the Victorian Engineer Henrietta Vansittart, Part 1. Electrifying Women.

58. Reilly ED, Rackley K, Awad GH (2016). Perceptions of male and female STEM aptitude: The moderating effect of benevolent and hostile sexism. Journal of Career Development; 44: 159-73.

59. Rosser S (2014). Breaking into the Lab: Engineering Progress for Women in Science. NYU Press.

60. Royal Academy of Engineering (RAE), (2020). Engineering gender pay gap in the UK less than feared, but still requires action. Roya Academy of Engineering.

61. Singh R, Fouad NA, Fitzpatrick ME, Liu JP, Cappaert KJ, Figuereido C (2013). Stemming the tide: predicting women engineers' intentions to leave. J. Vocat. Behav.; 83: 281-294.

62. Society of Women Engineers Blog (SWEB), (2017). History of Women Engineers. All Together Society of Women Engineers. Society of Women Engineers.

63. Stanley A (1993). Mothers and Daughters of Invention: Notes for a Revised History of Invention Metuchen, NJ and London: Scarecrow Press, 1993.

64. Statistics Canada Study (SCS), (2019). Gender Gaps: The Effects of Pay Transparency and Women in STEM Occupations," Statistics Canada Press Release.

65. Steinke J, Tavarez PMP (2016). Cultural representations of gender and science: portrayals of female STEM professionals in popular films 2002-2015. Paper Presented at the Association for Education in Journalism and Mass Communication, San Francisco, CA.

66. Torres-Carrion PV, Gonzalez-Gonzalez CS, Aciar S, RodriguezMorales G. (2018). Methodology for systematic literature review applied to engineering and education. 2018 IEEE Global Engineering Education Conference (EDUCON), Tenerife. Pp. 1364-1373.

67. UNESCO (2019). Institute for Statistics, Fact Sheet No. 55: Women in Science: p. 2.

68. Van Oosten EB, Buse K, Bilimoria D (2017). The Leadership Lab for Women: Advancing and Retaining Women in STEM through Professional Development. Front. Psychol.; 8:21-38.

69. Warren S, Goodman M, Horton R, Bynum N (2016). Stemming the tide: the presentation of women scientists in CSI. Int. J. Gen. Sci. Technol.; 8: 360-381.

70. White A (2018). The history of women in engineering on Wikipedia. Science Museum Group Journal 10:10.

71. Yang J (2016). The impact of power status on gender stereotypes, sexism, and gender discrimination toward women in the workplace and the career identity development of women. The University of North Dakota: The University of North Dakota. Pp. 1-20.

72. Yoder BL (2012). Engineering by the Numbers. ASEE. American Society for Engineering Education.

73. Yoder BL (2018). Engineering by the Numbers. American Society for Engineering Education.

74. Zenger J, Folkman J (2019). Research: Women Score Higher Than Men in Most Leadership Skills. Harvard Business Review.

\section{AUTHOR PROFILE}

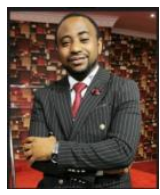

Dr. Kehdinga George Fomunyam, Institute for Systems Science, Durban University of Technology, Durban, South Africa.

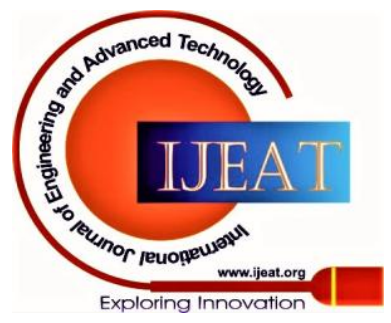

